\title{
Review Article \\ Mechanisms of Electroacupuncture-Induced Analgesia on Neuropathic Pain in Animal Model
}

\author{
Woojin Kim, ${ }^{1}$ Sun Kwang Kim, ${ }^{2}$ and Byung-II Min ${ }^{1,3}$ \\ ${ }^{1}$ Department of East-West Medicine, Graduate School, Kyung Hee University, Seoul 130-701, Republic of Korea \\ ${ }^{2}$ Department of Physiology, College of Korean Medicine, Kyung Hee University, Seoul 130-701, Republic of Korea \\ ${ }^{3}$ Department of Physiology, College of Medicine, Kyung Hee University, Seoul 130-701, Republic of Korea
}

Correspondence should be addressed to Byung-Il Min; mbi@khu.ac.kr

Received 20 February 2013; Revised 23 June 2013; Accepted 11 July 2013

Academic Editor: Lixing Lao

Copyright (C) 2013 Woojin Kim et al. This is an open access article distributed under the Creative Commons Attribution License, which permits unrestricted use, distribution, and reproduction in any medium, provided the original work is properly cited.

\begin{abstract}
Neuropathic pain remains as one of the most difficult clinical pain syndromes to treat. Electroacupuncture (EA), involving endogenous opioids and neurotransmitters in the central nervous system (CNS), is reported to be clinically efficacious in various fields of pain. Although multiple experimental articles were conducted to assess the effect of EA-induced analgesia, no review has been published to assess the efficacy and clarify the mechanism of EA on neuropathic pain. To this aim, this study was firstly designed to evaluate the EA-induced analgesic effect on neuropathic pain and secondly to guide and help future efforts to advance the neuropathic pain treatment. For this purpose, articles referring to the analgesic effect of acupuncture on neuropathic pain and particularly the work performed in our own laboratory were analyzed. Based on the articles reviewed, the role of spinal opioidergic, adrenergic, serotonergic, cholinergic, and GABAergic receptors in the mechanism of EA-induced analgesia was studied. The results of this research demonstrate that $\mu$ and $\delta$ opioid receptors, $\alpha_{2}$-adrenoreceptors, $5-\mathrm{HT}_{1 \mathrm{~A}}$ and $5-\mathrm{HT}_{3}$ serotonergic receptors, $\mathrm{M}_{1}$ muscarinic receptors, and $\mathrm{GABA}_{\mathrm{A}}$ and $\mathrm{GABA}_{\mathrm{B}} \mathrm{GABAergic}$ receptors are involved in the mechanisms of EA-induced analgesia on neuropathic pain.
\end{abstract}

\section{Introduction}

Acupuncture has been a widely used method in traditional medicine in East Asia for thousands of years. Since its introduction to western countries in the 1970s, the global interest in acupuncture has increased, and significant evidence supports acupuncture as a useful tool for treating a diverse spectrum of diseases. In fact, more than 40 disorders have been endorsed by the World Health Organization (WHO) as conditions that can benefit from acupuncture treatment [1]. Among these disorders, pain is known to be particularly sensitive to acupuncture and has been a compelling field for research. In a total of 3,975 acupuncture research articles published from 1991 to 2009, 1647 (41\%) focus on pain and analgesia [2].

Multiple theories of pain control mechanisms such as gate-control theory [3], spinal segmental mechanism [4], endogenous opioid system [5], descending noradrenergic and serotonergic systems [6], and diffuse noxious inhibitory control [7] have been investigated over the last several decades to clarify the mechanism of acupuncture and EA. Acupuncture is now proven to be clinically efficacious in various fields of pain, such as, lower back pain [8], chronic knee pain [9], and chronic headache [10], and a recent meta-analysis also demonstrates the effect of acupuncture on different types of chronic pain [11]. EA is a modified acupuncture technique that, as its name implies, utilizes electrical stimulation, and its analgesic effect on different types of acute pains and persistent inflammatory pains has appeared in both rodents and humans [12-14].

According to the NeuPSIG (Special Interest Group on Neuropathic Pain), neuropathic pain is defined as "pain arising as a direct consequence of a lesion or disease affecting the somatosensory system" [15]. It is often reported as having a lancinating or continuous burning character and is frequently associated with the appearance of abnormal sensory signs such as allodynia (pain as a result of a stimulus which normally does not provoke pain) or hyperalgesia 
(an increased response to a stimulus which is normally painful) [16]. The underlying mechanisms are complex and appear to involve both peripheral and central components of the nervous system [17].

The spectrum of neuropathic pain covers a variety of disease states and presents itself in the clinic through a variety of symptoms, namely, lumbar radiculopathy (lower back pain caused by disk compression or herniation), spinal cord injury, phantom pain, diabetic neuropathy, postherpetic neuralgia, and in some patients, fibromyalgia, and cancer-related pain [18].

It is estimated that neuropathic pain affects over 26 million patients worldwide, resulting in a worldwide healthcare cost of over $\$ 3$ billion per year, with a significant portion of this money paid to drug therapies that originally were developed for other medical conditions [19].

Current pharmacological treatment for neuropathic pain typically will include some combination of agents from several of the following drug classes: opioids, tricyclic antidepressants, anticonvulsant agents, or nonsteroidal antiinflammatory drugs (NSAIDs)/analgesics. Ironically, even with such an impressive arsenal of powerful drugs, these approaches only provide an approximate $30-50 \%$ reduction of pain in about $50 \%$ of patients. In addition, there are various side effects associated with these drugs [20, 21].

These results underscore the importance of considering a complementary and alternative neuropathic pain treatment. Previously, several clinical studies have shown the effectiveness of EA on various neuropathic pain diseases such as neuropathic pain of malignancy [22], diabetic neuropathy $[23,24]$, phantom limb pain $[25,26]$, and below-level central neuropathic pain [27]. However, although multiple reviews exist on the analgesic mechanisms of EA, no previous review has been published on the effect of EA in neuropathic pain, and still the mechanism that lies behind it remains unclear.

For many years, and since the publishing of the first article of Hwang et al. [28] on neuropathic pain published from our laboratory, our research has focused on clarifying the mechanisms of EA on neuropathic pain, and different experimental designs were used to understand the analgesic effect of EA in neuropathic pain rats. So far, the mechanisms of EA on spinal endogenous opioidergic [28-31] adrenergic and serotonergic [32], cholinergic [33, 34], and GABAergic [35] systems have been clarified as a result of these studies, and efforts to clarify further mechanisms are on their way [36].

To guide future efforts in the advancement of neuropathic pain treatment, we believed that a timely review was important. In this review, based on the articles published in our laboratory, we will proceed to expand on clarification of the effect of EA on neuropathic pain and quantify its mechanism.

\section{Endogenous Opioids and Descending Inhibitory System}

Since 1970, the mechanism of acupuncture analgesia has been broadly investigated, and numerous pieces of evidence demonstrated that acupuncture analgesia is mediated via neuronal mechanisms correlated with the central nervous system (CNS) $[6,37,38]$. The most recognized mechanisms are endogenous opiates mechanisms $[5,39]$ and descending inhibitory mechanisms [6]. Endogenous opioids are known to be mediated through its $\mu, \delta, \kappa$ receptors and descending inhibitory pathway through its monoaminergic neurotransmitters and their receptors. In this review, to clarify the mechanism of EA in neuropathic pain, we have focused on the neurotransmitters receptors present in the CNS, especially in the spinal level.

2.1. Opioidergic Receptors. Ever since the publication of the article by Arner and Meyerson in 1988 titled "lack of an effect of opioids on neuropathic and idiopathic forms of pain" [40], multiple studies have been published supporting the efficacy of opioids for neuropathic pain, and it is now known that opioids can clearly provide effective analgesia for neuropathic pain $[41,42]$. Endogenous opioids are involved in both ascending and descending parts of the inhibition pathway. In the ascending portion, all three receptors $(\mu, \delta$, $\kappa)$ play a part, but only $\mu$ and $\delta$ receptors are responsible in the descending portion [43].

The involvement of opioid receptors in mediating acupuncture analgesia is demonstrated in several articles. Han reported that EA analgesia is mediated by enkephalin, $\beta$-endorphin, endomorphin, and dynorphin released in the CNS and that $\mu, \delta, \kappa$ opioid receptors are involved in the mechanisms $[39,44]$. David Mayer clarified the role of endogenous opioid in the mechanisms proving that the analgesic effect of acupuncture was prevented or reversed by the opioid receptors blocker naloxone $[45,46]$.

To determine whether the EA analgesic effect is mediated by endogenous opioid in the rat model of neuropathic pain, Hwang et al. conducted an experiment by injecting opioid antagonist naloxone intraperitoneally $20 \mathrm{~min}$ before the EA in rat specimens [28]. The EA was applied at Houxi acupoint (SI3), and mechanical allodynia was assessed by a normally innocuous stimulation of the tail with the Von Frey Hair. An abrupt tail movement of more than $0.5 \mathrm{~cm}$ was considered to be an abnormal response attributed to mechanical allodynia. The results show that the antiallodynic effect of EA was reversed by intraperitoneal injected naloxone but not through normal saline. Further experimentation with intraperitoneal morphine also demonstrates that mechanical allodynia was relieved in a dose-dependent manner. The result reports that a higher dose $(1.5 \mathrm{mg} / \mathrm{kg})$ of morphine relieves more effectively the signs of mechanical allodynia than a lower dose $(0.5 \mathrm{mg} / \mathrm{kg})$ and that EA with $1.5 \mathrm{mg} / \mathrm{kg}$ of morphine induced a slightly more antiallodynic effect. These results are consistent with the previous results of Mayer and Omana $[46,47]$.

In addition, through cDNA microarray analysis and dotblot analysis, Ko et al. identified the opioid signaling events involved in neuropathic pain [31]. This data suggest that the opioid receptor probably plays an important role in the development of neuropathic pain and the analgesic effects of EA.

Furthermore, Kim et al. [29] conducted an experiment to clarify which opioidergic receptors are involved in 
the relieving effect of EA on mechanical allodynia in the spinal cord. Selective $\mu$ ( $\beta$-FNA), $\delta$ (naltrindole), and $\kappa$ (norBNI) antagonists were administered intrathecally separated by $10 \mathrm{~min}$ in cumulative doses to examine whether the effect of EA was blocked by these antagonists. The EA was also applied into Zusanli (ST36). Results show that relieving effects on mechanical allodynia are blocked by $\mu$ and $\delta$ selective opioid antagonists but not by $\kappa$ selective opioid antagonists. The fact that $\kappa$ selective opioid antagonist did not work might be due to the low frequency $(2 \mathrm{~Hz})$ used in the experiment. Chen and Han [48] and Wu et al. [49] reported that $2 \mathrm{~Hz}$ EA-induced analgesia is mediated by metenkephalin via $\mu, \delta$ receptors; however, the antinociception effect induced by high-frequency $(100 \mathrm{~Hz})$ EA is mediated by dynorphin via $\kappa$ receptors in the spinal cord of rats. This report is consistent with the review of Han [39].

Kim et al. [30] also reported that the increased expression level of CCK-A receptors, the site of action for the antiopioid peptide cholecystokinin (CCK) in the hypothalamus, might decrease the sensitivity of EA and result in the decrease of the analgesic effect and antiallodynic effect on neuropathic pain model rats. This result is supported by other studies of Lee et al. [50,51] reporting that the presence of CCK-A receptor might decrease the analgesic effect of EA.

2.2. Adrenergic Receptors. Noradrenalin (NE) is known to be one of the main transmitters involved in the descending inhibitory system with serotonin and opioids [43]. It was previously reported that noradrenergic inputs in the spinal cord originate from the locus coeruleus (LC) and adjacent noradrenergic nuclei in the brainstem [52]. Unlike the serotonergic axons descending from nucleus raphe magnus (NRM) and operating through enkephalinergic interneurons in the spinal cord, noradrenergic fibers are known to bring about direct inhibition on the many types of spinal cell with which they make synaptic contacts [53]. Supraspinal descending pathways are known to be the only source of NE in the spinal dorsal horn [54].

There are two major groups of adrenoreceptors, $\alpha$ and $\beta$, with several subtypes. Among these receptors, $\alpha_{1}$ - and $\alpha_{2}$-adrenoreceptors are shown to be largely involved in pain modulation [54], and results from recent studies indicate that both the $\alpha_{1}$ - and $\alpha_{2}$-adrenoreceptors are involved in neuropathic pain [55]. Some articles report that NE enhances the spinal GABAergic and cholinergic transmission by activating $\alpha_{1}$ - [56] and $\alpha_{2}$ - [57] adrenoreceptors. An analgesic effect in the rat, caused by intrathecal administered NE, has been shown to be blocked by phentolamine, a nonselective $\alpha$ adrenoreceptors antagonist [43]. Also, epidural injection of the $\alpha_{2}$-adrenoreceptors, clonidine, has been reported to result in pain relief in cancer patients with neuropathic pain [58].

To examine the role of $\alpha_{1}$ - and $\alpha_{2}$-adrenoreceptors in the mechanisms of EA, Kim et al. conducted a research administering one dose of $\alpha_{1}$ - and $\alpha_{2}$-adrenoreceptors antagonists (prazosin or yohimbine, resp.) intrathecally with EA. Needles were inserted into Zusanli (ST36), and $30 \mu \mathrm{g}$ of prazosin and yohimbine were injected to neuropathic pain rats [32]. The relieving effects of EA on cold allodynia were blocked by the $\alpha_{2}$-adrenoreceptors antagonist yohimbine but not by the $\alpha_{1}$-adrenoreceptors antagonist prazosin. This result shows that the effect of an EA analgesic might be mediated by the spinal $\alpha_{2}$-adrenoreceptors but not by the $\alpha_{1}$-adrenoreceptors. This data is consistent with Kim's et al. [59] previous study conducted with only $\alpha_{1}$ and $\alpha_{2}$-adrenoreceptor antagonists, prazosin, and yohimbine intraperitoneally administrated without the EA insertion. Jiang et al. and several other studies [60-63] also reported that intrathecal administration of the $\alpha_{2}$-adrenoreceptors agonist in a neuropathic pain model rats significantly attenuated hyperalgesia and tactile allodynia.

Contrary to the role of $\alpha_{2}$-adrenoreceptors, a lot of evidence and results from these experiments suggest that not only are spinal $\alpha_{1}$-adrenoreceptors not involved in pain inhibition $[64,65]$ but also they play an important role in the prenociception of animals and humans [66, 67]. These results are in agreement with other previous studies $[54,68,69]$ which show how in the nervous system $\alpha_{1}$ adrenoreceptors and $\alpha_{2}$-adrenoreceptors antagonist yohimbine work as an excitatory although $\alpha_{2}$-adrenoreceptors and $\alpha_{1}$-adrenoreceptors antagonist prazosin works as an inhibitory and demonstrate that spinal $\alpha_{2}$-adrenoreceptors are involved in the relieving effects of EA on cold allodynia.

2.3. Serotonergic Receptors. Serotonin is known to have antinociceptive effect spinally, depending on the receptor type activated and dosage use [70,71]. The role of serotonin in the descending inhibitory pathway of the CNS was also demonstrated $[72,73]$. The involvement of serotonin in the analgesic effect of EA was mentioned in an early study of Cheng and Pomeranz [74]. They previously hypothesized that two distinct pain relieving mechanisms are involved in the effects of EA, including endogenous endorphin and nonendorphin systems. They further reported that nonendorphinergic actions may be mediated by monoaminergic neurons such as serotonin and NE [13]. The analgesic effect of serotonin is reported to be mediated from periaqueductal grey (PAG), NRM, and serotonergic receptors present in the spinal dorsal horn [75]. The spinal release of opioid may be driven by a serotonergic descending pathway [76-78] and is at least in part elicited by activation of $5-\mathrm{HT}_{3}$ receptors [79]. The electrolytic lesion of the NRM, a procedure known to decrease the release of 5-HT in the spinal cord [80], attenuates EA-induced analgesia [81]. Research from a number of studies has demonstrated that analgesia by peripheral stimulation is mediated by the serotonergic pathway in the descending inhibitory system [82-84], and the involvement of serotonin receptors in the analgesic mechanism of acupuncture in a neuropathic pain model rat was shown in the study of Zhao [85]. Seven subtypes $\left(5-\mathrm{HT}_{1-7}\right)$ of serotonin receptors have been identified. $5-\mathrm{HT}_{1} 5-\mathrm{HT}_{2}$ or $5-\mathrm{HT}_{3}$ are known to be the most commonly implicated in the spinal analgesic effect induced by peripheral stimulation [86-88].

However, conflicting results have been reported regarding the involvement of these three 5-HT receptors. Horiuchi et al. [89] reported that intrathecal administration of $5-\mathrm{HT}_{1 \mathrm{~A}}$ and $5-\mathrm{HT}_{3}$ but not $5-\mathrm{HT}_{2 \mathrm{~A}}$ receptor agonists inhibited thermal hyperalgesia induced by spinal cord injury. Chang et al. [13] are in agreement with Horiuchi et al. and showed that 
intracerebroventricular administration of $5-\mathrm{HT}_{1 \mathrm{~A}}$ and $5-\mathrm{HT}_{3}$ but not $5-\mathrm{HT}_{2 \mathrm{~A}}$ receptor antagonists blocked the analgesic effect induced by EA. Baek et al. [12] also demonstrated that in the rat model of collagen-induced arthritis the analgesic effect of EA was blocked by intraperitoneal pretreatment of $5-\mathrm{HT}_{1 \mathrm{~A}}$ receptor antagonist and $5-\mathrm{HT}_{3}$ receptor antagonist but not by $5-\mathrm{HT}_{2}$ receptor antagonist. These results suggest that the EA analgesic effect can be mediated by $5-\mathrm{HT}_{1 \mathrm{~A}}$ and $5-\mathrm{HT}_{3}$ receptors but not by a $5-\mathrm{HT}_{2 \mathrm{~A}}$ receptor.

Conversely, Radhakrishnan et al. [88] by administrating different 5-HT subtype antagonist intrathecally showed that spinal $5-\mathrm{HT}_{2 \mathrm{~A}}$ and $5-\mathrm{HT}_{3}$ but not $5-\mathrm{HT}_{1 \mathrm{~A}}$ receptors mediate transcutaneous electrical nerve stimulation (TENS) and induced antihyperalgesia in inflammatory pain model rats. Takagi and Yonehara [90] also reported that intravenously injected $5-\mathrm{HT}_{1}$, except $5-\mathrm{HT}_{1 \mathrm{~A}}, 5-\mathrm{HT}_{2}$, except $5-\mathrm{HT}_{2 \mathrm{~A}}$, and $5-\mathrm{HT}_{3}$ receptors are involved in EA-induced analgesia.

Thus, to clarify which serotonin receptor is involved in the spinal mechanisms of EA analgesia on neuropathic pain in rats, Kim et al. conducted a further study [32]. Serotonin receptor antagonists of $5-\mathrm{HT}_{1 \mathrm{~A}}(\mathrm{NAN}-190,15 \mu \mathrm{g}), 5-\mathrm{HT}_{2 \mathrm{~A}}$ (ketanserin, $30 \mu \mathrm{g}$ ), and 5- $\mathrm{HT}_{3}$ (MDL-72222, $12 \mu \mathrm{g}$ ) were injected intrathecally and needles were inserted into Zusanli (ST36). The relieving effect of EA on cold allodynia was blocked by the $5-\mathrm{HT}_{1 \mathrm{~A}}$ antagonist (NAN-190) and by the 5$\mathrm{HT}_{3}$ antagonist (MDL-72222) significantly, but not by the 5$\mathrm{HT}_{1}$ antagonist (ketanserin). This result is consistent with previous studies showing that $5-\mathrm{HT}_{1 \mathrm{~A}}$ receptors [91-93] and $5-\mathrm{HT}_{3}$ receptors [94-96] have antinociceptive roles.

Also, evidence suggests that $5-\mathrm{HT}_{1 \mathrm{~A}}$ receptors inhibit the nociceptive sign in the second-order spinothalamic tract [97], and $5-\mathrm{HT}_{3}$ involves GABAergic, ENKergic (enkephalinergic), and other classes of spinal intrinsic neurons at the spinal level [82, 98-101].

The discordance with the previous result of Radhakrishnan et al. and Takagi and Yonehara might be due to a difference in experiment design, as Radhakrishnan investigated on the inflammation of the knee joint and used TENS but not EA. And Yonehara investigated in the trigeminal nucleus caudalis in rabbits.

2.4. Cholinergic Receptors. Cholinergic receptors are known to have both excitatory and inhibitory actions. They mediate acetylcholine $(\mathrm{ACh})$ and induce an analgesic effect by the activation of spinal nicotinic or muscarinic acetylcholine receptors. Both the nicotinic and muscarinic receptors are located in the superficial and deep dorsal horn of the spinal cord where nociceptive information is transmitted and modulated $[54,57,102]$. Cholinergic innervations of the dorsal spinal cord are known to be primarily intrinsic [57], but evidence for cholinergic fibers descending from the brainstem to the spinal cord has also appeared as a result of several studies $[103,104]$.

The role of nicotinic and muscarinic receptors in the mechanisms of analgesia is known to be different. A large majority of studies indicate that antinociceptive and antiallodynic effects of cholinergic drugs are mediated mainly by the muscarinic receptors but not by the nicotinic receptors [57, 105-107]. Also, previous studies reported that systemic administration of atropine (nonselective muscarinic antagonist) prevented the analgesic effects of EA $[12,108]$.

To investigate whether spinal nicotinic or muscarinic receptors are involved in the relieving effects of EA on cold and warm allodynia, Park et al. conducted research with intrathecally administered atropine (nonselective muscarinic antagonist) and mecamylamine (nonselective nicotinic antagonist) on neuropathic pain model rats [34]. The relieving effects of EA on both cold allodynia and warm allodynia were completely blocked by atropine but not by mecamylamine. This outcome showed that the antiallodynic effect of EA in neuropathic pain rats is mediated mainly by the muscarinic receptor.

A further study was conducted by Park et al. [34], to determine which muscarine receptor subtype is involved in the antiallodynic action of EA. Currently, five classes of muscarinic receptor have been identified (i.e., $\mathrm{M}_{1-5}$ ). However, the subtypes implicated in the spinal nociceptive transmission and modulations are known to be consisting of $M_{1}, M_{2}$, and $M_{3}[106,107,109]$. Pirenzepine $\left(M_{1}\right.$ muscarinic receptor antagonist), methoctramine $\left(\mathrm{M}_{2}\right.$ muscarinic antagonist), and 4-DAMP ( $\mathrm{M}_{3}$ muscarinic antagonist) were injected intrathecally on rats, and acupuncture needles were inserted into "Zusanli" (ST36). Among these three antagonists, only pirenzepine $\left(\mathrm{M}_{1}\right.$ muscarinic receptor antagonist) completely blocked the relieving effect of EA on cold allodynia and warm allodynia, whereas methoctramine and 4-DAMP did not.

Kim et al. [33], with intrathecally administered cholinesterase inhibitor neostigmine, showed that EA has an effect that is equivalent to $0.1 \mu \mathrm{g}$ of neostigmine on neuropathic pain rats. Neostigmine is known to induce analgesia by mediating spinal muscarinic system and especially at the $M_{1}$ receptor subtype. On the other hand, neostigmine is also known to produce dose-dependent side effects such tremor, writhing action, or urination at doses of $0.3,1$ and $3 \mu \mathrm{g}$, in some rats $[110,111]$. However, the combination of intrathecal neostigmine $(0.1 \mu \mathrm{g})$ and EA stimulation produced a synergetic effect lasting more than $80 \mathrm{~min}$., becoming maximal at $20 \mathrm{~min}$., the same as a dose of $0.3 \mu \mathrm{g}$ of neostigmine, but without side effects. In summary, these results demonstrate that EA stimulation activates spinal $M_{1}$ muscarinic receptors to relieve cold and warm allodynia signs in neuropathic pain rats. This conclusion is in agreement with previous studies showing that $M_{1}$ receptor subtype mediates spinal antinociception and antiallodynia [105, 107, 112-114].

2.5. GABAergic Receptors. One of the major inhibitory neuropeptides, GABA is known to be contained in the PAG and plays an important role in the descending pain control pathway of the CNS [115-118]. It is also reported to be involved in multiple physiological and pathological functions. In the spinal cord, GABA exerts tonic modulation of nociceptive neurotransmission between primary afferents and second-order spinothalamic tract neurons [119, 120]. Intrathecally injected baclofen $\left(\mathrm{GABA}_{\mathrm{B}}\right.$ receptor agonist) has been demonstrated to produce analgesia in animal models of acute and neuropathic pain [121]. Three GABA receptor subtypes have been identified: $G_{A B A}, G A B A_{B}$, and $\mathrm{GABA}_{\mathrm{C}}[120]$, but it has been known that $\mathrm{GABA}_{\mathrm{A}}$ and 
$\mathrm{GABA}_{\mathrm{B}}$ receptors, present in the spinal cord [122], mainly contribute to modulation of pain $[54,123]$. Also, $\mathrm{GABA}_{\mathrm{A}}$ and $\mathrm{GABA}_{\mathrm{B}}$ receptor agonists have been demonstrated to have antinociceptive effects in a variety of rodent models [124]. The role of GABA and its receptors, in the acupuncture analgesia, has been demonstrated by several studies. Han et al. [125] reported that the microinjecting of muscimol, a GABA receptor agonist, or 3-MP, a GABA synthesis inhibitor, into the PAG remarkably potentiated or suppressed acupuncture analgesia, respectively. And Fusumada et al. [126] proved that by inserting EA at "Zusanli" (ST36), EA could induce analgesic effect along with the increasing expression of GABA in PAG. Also, Fu and Longhurst [127] and Tjen-A-Looi et al. [128] studies reported that EA decreases the release of GABA in ventrolateral PAG, by modulating the sympathoexcitatory reflex responses through endocannabinoids. These results are in line with the study of Fusumada as the decrease of GABA release may result in the increase of GABA in PAG.

First, Park et al. conducted research to investigate whether spinal GABAergic receptors are involved in the relieving effects of EA on cold allodynia in a rat tail model of neuropathic pain [35]. EA stimulation was applied to "Zusanli" (ST36) and rats were intrathecally injected with gabazine $\left(\mathrm{GABA}_{\mathrm{A}}\right.$ receptor antagonist, $0.0003,0.001$, or $\left.0.003 \mu \mathrm{g}\right)$ or saclofen $\left(\mathrm{GABA}_{\mathrm{B}}\right.$ receptor antagonist, 3, 10, or $\left.30 \mu \mathrm{g}\right)$. The relieving effect of EA on cold allodynia on neuropathic pained rats was blocked by gabazine at a dose of 0.001 or $0.003 \mu \mathrm{g}$. Saclofen also blocked the effect of EA-induced analgesic effect at a dose of 10 or $30 \mu \mathrm{g}$. The results show that both the $\mathrm{GABA}_{\mathrm{A}}$ and $\mathrm{GABA}_{\mathrm{B}}$ receptor antagonists dose dependently blocked the relieving effects of EA on cold allodynia. Also, these findings are consistent with the previous studies of Zhu et al. [129, 130], in which intrathecal administration of $\mathrm{GABA}_{\mathrm{A}}$ and $\mathrm{GABA}_{\mathrm{B}}$ receptor antagonists partially blocked the acupuncture analgesia. In brief, this evidence supports EA-induced antiallodynia as partially mediated by the activation of spinal inhibitory receptors including GABA receptors. Therefore, it is possible that EA treatment could enhance the analgesic effects of the GABAergic drugs, such as GABA agonists, on neuropathic pain in clinics and vice versa.

\section{Summary and Discussion}

Neuropathic pain is a complex phenomenon, involving several independent pathophysiological mechanisms in both peripheral and CNS. The accurate mechanisms of neuropathic pain and the relationships between its mechanisms, signs, and symptoms are not fully understood, and no consensus on the optimal management of neuropathic pain has been established yet. Although acupuncture's mechanisms of antinociception have not been fully explained, due to the overwhelming amount of research investigated in the last several decades, its analgesic effects are gradually being understood.

In this review, based on published reports from several research laboratories around the world and particularly the work performed in our laboratory, we demonstrated that spinal opioidergic, adrenergic, serotonergic, cholinergic, and GABAergic systems mediate the analgesic effects of EA in neuropathic pain rats. Data from our experiments show that spinal $\mu$ and $\delta$ opioid receptors, $\alpha_{2}$-adrenoreceptors, 5 - $\mathrm{HT}_{1 \mathrm{~A}}$ and 5- $\mathrm{HT}_{3}$ serotonergic receptors, $\mathrm{M}_{1}$ muscarinic receptors, and $\mathrm{GABA}_{\mathrm{A}}$ and $\mathrm{GABA}_{\mathrm{B}}$ GABAergic receptors are involved in the analgesic effect of EA on neuropathic pain, mediated by the descending inhibitory system in the CNS (Figure 1).

The descending inhibitory pathway consisted of hypothalamus-PAG-rostal ventromedial medulla (RVM)dorsal horn and mediates the release of serotonin in the PAG and NE in LC. NE, via $\alpha_{2}$-adrenoreceptors in the dorsal horn, enhances the spinal cholinergic and GABAergic intrinsic neurons, involves a reduction in the release of pronociceptive transmitters in the primary afferents fibers, and inhibits the transmission of pain signals to the supraspinal level in the secondary afferents fibers [131]. Serotonin activates enkephalin (ENK) and GABA spinal intrinsic neurons through $5-\mathrm{HT}_{3}$ serotonergic receptors and inhibits secondary afferents fiber via $5-\mathrm{HT}_{1 \mathrm{~A}}$ serotonergic receptors [54]. Spinal cholinergic, ENKergic, GABAergic neurons, through its $M_{1}$ muscarinic receptors, $\mu, \delta$ opioid receptors, and $\mathrm{GABA}_{\mathrm{A} / \mathrm{B}}$ receptors control nociceptive inputs from the periphery to higher areas in the CNS [54, 57]. The EA stimulation is carried up from marginal (M) cells tract to the brain via spinothalamic tract, where the signal is transmitted to the cortex and becomes conscious, and also to intrinsic dorsal neurons where it involves cholinergic, ENKergic, and GABAergic neurons [53, 121, 132].

Also, the role of glial activation on EA-induced analgesia should be considered alongside the mechanisms of neurons, as microglial activation has been reported to contribute to the initiation of pathological pain responses and astrocytic activation to pain maintenance in a rat model of neuropathic pain $[133,134]$. The involvement of glial activation in the analgesic effect of EA is demonstrated in the article of Wang et al. [135], and Gim et al. [36] reported recently that repeated EA attenuates mechanical and warm allodynia by suppressing microglial and astrocyte activation inhibiting the release of proinflammatory cytokine such as TNF- $\alpha$, IL-6, and IL-1 $\beta$.

Most of the articles included in this review used mechanical allodynia and thermal allodynia (warm or cold) to assess the effect of EA. However, they are reported to be mediated differently. Shir and Seltzer [136] demonstrated in his work that mechanical allodynia is mediated by Afibers and thermal allodynia by C-fibers. Among the works included in this review, Hwang et al. [28] and Kim et al. [29] used mechanical allodynia, while Kim et al. $[32,59]$, Park et al. [34, 35], and Kim et al. [33] used thermal allodynia to assess the effect of EA on neuropathic pain model rat. On mechanical allodynia the effect of EA marked significant increase up to $20 \mathrm{~min}$ after $30 \mathrm{~min}$ of EA administration [28], while on thermal allodynia, the EA group showed statistically significant increases in response to latency for up to $50 \mathrm{~min}$ after $30 \mathrm{~min}$ of EA insertion [32]. These results suggest that the analgesic effect of EA may be more efficacious on thermal allodynia than on mechanical allodynia.

This review is based on articles with animal experience and does not include any controlled clinical trial. Some controlled clinical trials have been published previously to assess the effectiveness of EA on neuropathic pain; however, the data 


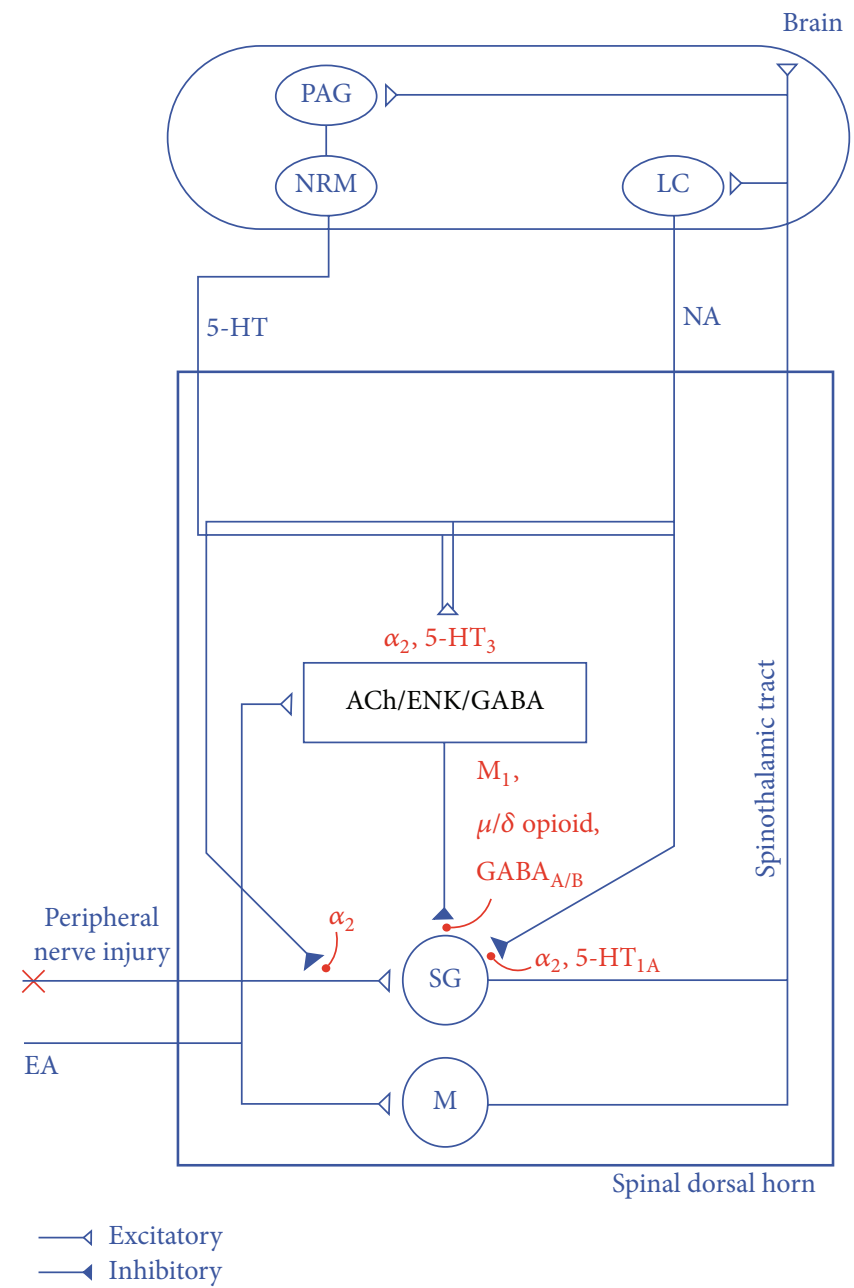

FIGURE 1: Schematic diagram of EA-induced analgesia in neuropathic pain in the CNS. The peripheral injury information is first transmitted to substantia gelatinosa (SG) cells by primary afferent fibers. EA stimulation is carried up from marginal (M) cells tract to the brain via spinothalamic tract, where the signal is transmitted to the cortex and becomes conscious and also to intrinsic dorsal neurons where it involves cholinergic, ENKergic, and GABAergic neurons. The PAG in the midbrain projects down to the NRM in the middle of the medulla oblongata, and this in turn sends 5-HT fibers to the dorsal horn. LC sends NE fibers to the dorsal horn. NE, via $\alpha_{2}$-adrenoreceptors, enhances the spinal cholinergic and GABAergic neurons, involves a reduction in the release of pronociceptive transmitters in the primary afferents fibers, and inhibits the transmission of pain signals to the supraspinal level in the secondary afferents fibers. Serotonin activates enkephalin (ENK) and GABA intrinsic neurons through $5-\mathrm{HT}_{3}$ serotonergic receptors and inhibits secondary afferents fibers via 5- $\mathrm{HT}_{1 \mathrm{~A}}$ serotonergic receptors. Cholinergic, ENKergic, GABAergic neurons, through its $M_{1}$ muscarinic receptors, $\mu, \delta$ opioid receptors, and $\mathrm{GABA}_{\mathrm{A}}$ and $\mathrm{GABA}_{\mathrm{B}}$ receptors control nociceptive inputs from the periphery to higher areas in the CNS. Abbreviations are as follows: SG: substantia gelatinosa; M: marginal cells; PAG: periaqueductal grey; NRM: nucleus raphe magnus; LC: locus coeruleus; 5-HT: serotonin; NE: noradrenalin; Ach: acetylcholine; and ENK: enkephalin.

are still controversial, and the number of controlled clinical trials is insufficient to determine its role in the clinic [137, 138]. Although, there are still no randomized clinical trials to support the analgesic effect of EA on neuropathic pain in clinic, we believe that various experimental models and results reported from the work included in our review could guide future efforts to publish a well-designed randomized clinical trial on neuropathic pain.

\section{Conclusion}

In conclusion, based on results from our study, we can conclude that both endogenous opioid system and descending inhibitory system mediate the antiallodynic mechanism of $\mathrm{EA}$, and that spinal opioidergic, adrenergic, serotonergic, cholinergic and GABAergic systems are involved in the mechanisms. Also, these results suggest that EA can be an efficacious complementary and alternative treatment to relieve the neuropathic pain.

Furthermore, since a functional interrelationship exists among the opioidergic, noradrenergic, serotonergic, cholinergic and GABAergic systems in the spinal dorsal horn and supraspinal level $[54,57]$, further studies should investigate how those receptors interact and to what degree each receptor system contributes independently to EA induced analgesia. 


\section{References}

[1] G. Stux, B. Berman, and B. Pomeranz, Basics of Acupuncture, Springer, 2003.

[2] M. K. Lee, S. R. Han, M. K. Park, M. J. Kim, Y. C. Bae, S. K. Kim et al., "Behavioral evidence for the differential regulation of p-p38 MAPK and p-NF-kappaB in rats with trigeminal neuropathic pain," Molecular Pain, vol. 7, p. 57, 2011.

[3] R. Melzack and P. D. Wall, "Pain mechanisms: a new theory," Science, vol. 150, no. 3699, pp. 971-979, 1965.

[4] Z. Bing, L. Villanueva, and D. Le Bars, "Acupuncture-evoked responses of subnucleus reticularis dorsalis neurons in the rat medulla," Neuroscience, vol. 44, no. 3, pp. 693-703, 1991.

[5] B. Pomeranz and D. Chiu, "Naloxone blockade of acupuncture analgesia: endorphin implicated," Life Sciences, vol. 19, no. 11, pp. 1757-1762, 1976.

[6] C. Takeshige, T. Sato, T. Mera, T. Hisamitsu, and J. Fang, "Descending pain inhibitory system involved in acupuncture analgesia," Brain Research Bulletin, vol. 29, no. 5, pp. 617-634, 1992.

[7] D. Le Bars, A. H. Dickenson, and J. M. Besson, "Diffuse noxious inhibitory controls (DNIC). I. Effects on dorsal horn convergent neurones in the rat," Pain, vol. 6, no. 3, pp. 283-304, 1979.

[8] C. P. O. Carlsson and B. H. Sjölund, "Acupuncture for chronic low back pain: a randomized placebo-controlled study with long-term follow-up," Clinical Journal of Pain, vol. 17, no. 4, pp. 296-305, 2001.

[9] A. White, N. E. Foster, M. Cummings, and P. Barlas, "Acupuncture treatment for chronic knee pain: a systematic review," Rheumatology, vol. 46, no. 3, pp. 384-390, 2007.

[10] A. J. Vickers, R. W. Rees, C. E. Zollman et al., "Acupuncture for chronic headache in primary care: large, pragmatic, randomised trial," British Medical Journal, vol. 328, no. 7442, pp. 744-747, 2004.

[11] A. J. Vickers, A. M. Cronin, A. C. Maschino, G. Lewith, H. MacPherson, N. E. Foster et al., "Acupuncture for chronic pain: individual patient data meta-analysis," Archives of Internal Medicine, vol. 172, no. 19, pp. 1444-1453, 2012.

[12] Y. H. Baek, Y. C. Do, I. Y. Hyung, and D. S. Park, "Analgesic effect of electroacupuncture on inflammatory pain in the rat model of collagen-induced arthritis: mediation by cholinergic and serotonergic receptors," Brain Research, vol. 1057, no. 1-2, pp. 181-185, 2005.

[13] F.-C. Chang, H.-Y. Tsai, M.-C. Yu, P.-L. Yi, and J.-G. Lin, "The central serotonergic system mediates the analgesic effect of electroacupuncture on zusanli (ST36) acupoints," Journal of Biomedical Science, vol. 11, no. 2, pp. 179-185, 2004.

[14] A. Li, Y. Wang, J. Xin et al., "Electroacupuncture suppresses hyperalgesia and spinal Fos expression by activating the descending inhibitory system," Brain Research, vol. 1186, no. 1, pp. 171-179, 2007.

[15] R.-D. Treede, T. S. Jensen, J. N. Campbell et al., "Neuropathic pain: redefinition and a grading system for clinical and research purposes," Neurology, vol. 70, no. 18, pp. 1630-1635, 2008.

[16] D. Bridges, S. W. N. Thompson, and A. S. C. Rice, "Mechanisms of neuropathic pain," British Journal of Anaesthesia, vol. 87, no. 1, pp. 12-26, 2001.

[17] C. J. Woolf and R. J. Mannion, "Neuropathic pain: aetiology, symptoms, mechanisms, and management," Lancet, vol. 353, no. 9168, pp. 1959-1964, 1999.

[18] J. W. Scadding and M. Koltzenburg, "Painful peripheral neuropathies," in Wall and Melzack's Textbook of Pain, S. B.
McMahon and M. Koltzenburg, Eds., pp. 973-999, Elsevier, 2006.

[19] N. Pain, J. A. Butera, and M. R. Brandt, "section I. central nervous system diseases," Annual Reports in Medicinal Chemistry, vol. 38, p. 1, 2003.

[20] J. A. Butera, "Current and emerging targets to treat neuropathic pain," Journal of Medicinal Chemistry, vol. 50, no. 11, pp. 25432546, 2007.

[21] V. L. Tawfik, N. Nutile-McMenemy, M. L. LaCroix-Fralish, and J. A. DeLeo, "Efficacy of propentofylline, a glial modulating agent, on existing mechanical allodynia following peripheral nerve injury," Brain, Behavior, and Immunity, vol. 21, no. 2, pp. 238-246, 2007.

[22] J. Filshie, "The non-drug treatment of neuralgic and neuropathic pain of malignancy," Cancer Surveys, vol. 7, no. 1, pp. 161193, 1988.

[23] B. B. Abuaisha, J. B. Costanzi, and A. J. M. Boulton, "Acupuncture for the treatment of chronic painful peripheral diabetic neuropathy: a long-term study," Diabetes Research and Clinical Practice, vol. 39, no. 2, pp. 115-121, 1998.

[24] P. J. Goodnick, K. Breakstone, X.-L. Wen, and A. Kumar, "Acupuncture and neuropathy," American Journal of Psychiatry, vol. 157, no. 8, pp. 1342-1343, 2000.

[25] R. A. Carabelli and W. C. Kellerman, "Phantom limb pain: relief by application of TENS to contralateral extremity," Archives of Physical Medicine and Rehabilitation, vol. 66, no. 7, pp. 466-467, 1985.

[26] V. Finsen, L. Persen, M. Lovlien et al., "Transcutaneous electrical nerve stimulation after major amputation," Journal of Bone and Joint Surgery B, vol. 70, no. 1, pp. 109-112, 1988.

[27] L. M. Rapson, N. Wells, J. Pepper, N. Majid, and H. Boon, "Acupuncture as a promising treatment for below-level central neuropathic pain: a retrospective study," Journal of Spinal Cord Medicine, vol. 26, no. 1, pp. 21-26, 2003.

[28] B. G. Hwang, B.-I. Min, J. H. Kim, H. S. Na, and D. S. Park, "Effects of electroacupuncture on the mechanical allodynia in the rat model of neuropathic pain," Neuroscience Letters, vol. 320, no. 1-2, pp. 49-52, 2002.

[29] J. H. Kim, B.-I. Min, H. S. Na, and D. S. Park, "Relieving effects of electroacupuncture on mechanical allodynia in neuropathic pain model of inferior caudal trunk injury in rat: mediation by spinal opioid receptors," Brain Research, vol. 998, no. 2, pp. 230236, 2004.

[30] S. K. Kim, H. J. Moon, J. H. Park et al., "The maintenance of individual differences in the sensitivity of acute and neuropathic pain behaviors to electroacupuncture in rats," Brain Research Bulletin, vol. 74, no. 5, pp. 357-360, 2007.

[31] J. Ko, S. N. Doe, H. L. Young et al., "cDNA microarray analysis of the differential gene expression in the neuropathic pain and electroacupuncture treatment models," Journal of Biochemistry and Molecular Biology, vol. 35, no. 4, pp. 420-427, 2002.

[32] S. K. Kim, J. H. Park, S. J. Bae et al., "Effects of electroacupuncture on cold allodynia in a rat model of neuropathic pain: mediation by spinal adrenergic and serotonergic receptors," Experimental Neurology, vol. 195, no. 2, pp. 430-436, 2005.

[33] H. N. Kim, J. H. Park, S. K. Kim et al., "Electroacupuncture potentiates the antiallodynic effect of intrathecal neostigmine in a rat model of neuropathic pain," Journal of Physiological Sciences, vol. 58, no. 5, pp. 357-360, 2008.

[34] J. H. Park, S. K. Kim, H. N. Kim et al., "Spinal cholinergic mechanism of the relieving effects of electroacupuncture on cold and warm allodynia in a rat model of neuropathic pain," Journal of Physiological Sciences, vol. 59, no. 4, pp. 291-298, 2009. 
[35] J.-H. Park, J.-B. Han, S.-K. Kim et al., "Spinal GABA receptors mediate the suppressive effect of electroacupuncture on cold allodynia in rats," Brain Research, vol. 1322, pp. 24-29, 2010.

[36] G.-T. Gim, J.-H. Lee, E. Park et al., "Electroacupuncture attenuates mechanical and warm allodynia through suppression of spinal glial activation in a rat model of neuropathic pain," Brain Research Bulletin, vol. 86, no. 5-6, pp. 403-411, 2011.

[37] J. Filshie and A. White, Medical Acupuncture: A Western Scientific Approach, Churchill livingstone, Edinburgh, UK, 1998.

[38] J. S. Han, The Neurochemical Basis of Pain Relief by Acupuncture, Chinese Medical Science and Technology Press, Beijing, China, 1987.

[39] J. S. Han, “Acupuncture and endorphins," Neuroscience Letters, vol. 361, no. 1-3, pp. 258-261, 2004.

[40] S. Arner and B. A. Meyerson, "Lack of analgesic effect of opioids on neuropathic and idiopathic forms of pain," Pain, vol. 33, no. 1, pp. 11-23, 1988.

[41] E. Eisenberg, E. D. McNicol, and D. B. Carr, "Efficacy and safety of opioid agonists in the treatment of neuropathic pain of nonmalignant origin: systematic review and meta-analysis of randomized controlled trials," Journal of the American Medical Association, vol. 293, no. 24, pp. 3043-3052, 2005.

[42] H. S. Smith, "Opioids and neuropathic pain," Pain Physician, vol. 15, no. 3, supplement, pp. ES93-ES110, 2012.

[43] J. A. Stamford, "Descending control of pain," British Journal of Anaesthesia, vol. 75, no. 2, pp. 217-227, 1995.

[44] J.-S. Han, "Acupuncture: neuropeptide release produced by electrical stimulation of different frequencies," Trends in Neurosciences, vol. 26, no. 1, pp. 17-22, 2003.

[45] D. J. Mayer, "Acupuncture: an evidence-based review of the clinical literature," Annual Review of Medicine, vol. 51, pp. 4963, 2000.

[46] D. J. Mayer, D. D. Price, and A. Rafii, "Antagonism of acupuncture analgesia in man by the narcotic antagonist naloxone," Brain Research, vol. 121, no. 2, pp. 368-372, 1977.

[47] I. Omana, V. Olvera, P. Santos, and J. L. Calderon, "Naloxone prevents reduction of pain responses evoked by acupuncture in neuropathic rats," Proceedings of the Western Pharmacology Society, vol. 37, pp. 135-136, 1994.

[48] X.-H. Chen and J.-S. Han, "All three types of opioid receptors in the spinal cord are important for $2 / 15 \mathrm{~Hz}$ electroacupuncture analgesia," European Journal of Pharmacology, vol. 211, no. 2, pp. 203-210, 1992.

[49] L.-Z. Wu, C.-L. Cui, J.-B. Tian, D. Ji, and J.-S. Han, "Suppression of morphine withdrawal by electroacupuncture in rats: dynorphin and $\kappa$-opioid receptor implicated," Brain Research, vol. 851, no. 1-2, pp. 290-296, 1999.

[50] G. Lee, S. Rho, M. Shin, M. Hong, B.-I. Min, and H. Bae, "The association of cholecystokinin-A receptor expression with the responsiveness of electroacupuncture analgesic effects in rat," Neuroscience Letters, vol. 325, no. 1, pp. 17-20, 2002.

[51] G. S. Lee, J. B. Han, M. K. Shin, M. C. Hong, S. W. Kim, B. I. Min et al., "Enhancement of electroacupuncture-induced analgesic effect in cholecystokinin-a receptor deficient rats," Brain Research Bulletin, vol. 62, no. 2, pp. 161-164, 2003.

[52] W. Ma and J. C. Eisenach, "Chronic constriction injury of sciatic nerve induces the up-regulation of descending inhibitory noradrenergic innervation to the lumbar dorsal horn of mice," Brain Research, vol. 970, no. 1-2, pp. 110-118, 2003.

[53] D. Bowsher, Mechanisms of Acupuncture. Western Acupuncture: A Western Scientific Approach Edinburgh, UK, Churchill Livingstone, 1998.
[54] M. J. Millan, “Descending control of pain," Progress in Neurobiology, vol. 66, no. 6, pp. 355-474, 2002.

[55] A. H. Hord, D. D. Denson, B. Stowe, and R. M. Haygood, “ $\alpha$ 1 and $\alpha$-2 adrenergic antagonists relieve thermal hyperalgesia in experimental mononeuropathy from chronic constriction injury," Anesthesia and Analgesia, vol. 92, no. 6, pp. 1558-1562, 2001.

[56] H. Baba, K. Shimoji, and M. Yoshimura, "Norepinephrine facilitates inhibitory transmission in substantia gelatinosa of adult rat spinal cord (Part 1): effects of axon terminals of GABAergic and glycinergic neurons," Anesthesiology, vol. 92, no. 2, pp. 473-484, 2000.

[57] J. C. Eisenach, "Muscarinic-mediated analgesia," Life Sciences, vol. 64, no. 6-7, pp. 549-554, 1999.

[58] J. C. Eisenach, S. DuPen, M. Dubois, R. Miguel, and D. Allin, "Epidural clonidine analgesia for intractable cancer pain," Pain, vol. 61, no. 3, pp. 391-399, 1995.

[59] S. K. Kim, B.-I. Min, J. H. Kim et al., "Effects of $\alpha_{1}$ - and $\alpha_{2}$ adrenoreceptor antagonists on cold allodynia in a rat tail model of neuropathic pain," Brain Research, vol. 1039, no. 1-2, pp. 207210, 2005.

[60] J.-X. Hao, W. Yu, X.-J. Xu, and Z. Wiesenfeld-Hallin, "Effects of intrathecal vs. systemic clonidine in treating chronic allodynialike response in spinally injured rats," Brain Research, vol. 736, no. 1-2, pp. 28-34, 1996.

[61] L.-Y. Jiang, S.-R. Li, F.-Y. Zhao, D. Spanswick, and M.-T. Lin, "Norepinephrine can act via $\alpha_{2}$-adrenoceptors to reduce the hyper-excitability of spinal dorsal horn neurons following chronic nerve injury," Journal of the Formosan Medical Association, vol. 109, no. 6, pp. 438-445, 2010.

[62] T. J. Martin and J. C. Eisenach, "Pharmacology of opioid and nonopioid analgesics in chronic pain states," Journal of Pharmacology and Experimental Therapeutics, vol. 299, no. 3, pp. 811-817, 2001.

[63] M. Namaka, C. Leong, A. Grossberndt et al., "A treatment algorithm for neuropathic pain: an update," Consultant Pharmacist, vol. 24, no. 12, pp. 885-902, 2009.

[64] R. M. Danzebrink and G. F. Gebhart, "Antinociceptive effects of intrathecal adrenoceptor agonists in a rat model of visceral nociception," Journal of Pharmacology and Experimental Therapeutics, vol. 253, no. 2, pp. 698-705, 1990.

[65] J. F. Miller and H. K. Proudfit, "Antagonism of stimulationproduced antinociception from ventrolateral pontine sites by intrathecal administration of $\alpha$-adrenergic antagonists and naloxone," Brain Research, vol. 530, no. 1, pp. 20-34, 1990.

[66] P. D. Drummond, S. Skipworth, and P. M. Finch, " $\alpha_{1}$ Adrenoceptors in normal and hyperalgesic human skin," Clinical Science, vol. 91, no. 1, pp. 73-77, 1996.

[67] A. K. Ouseph and J. D. Levine, " $\alpha_{1}$-Adrenoceptor-mediated sympathetically dependent mechanical hyperalgesia in the rat," European Journal of Pharmacology, vol. 273, no. 1-2, pp. 107-112, 1995.

[68] T. Akasu, J. P. Gallagher, and T. Nakamura, "Noradrenaline hyperpolatization and depolarization in cat vesical parasympathetic neurones," Journal of Physiology, vol. 361, pp. 165-184, 1985.

[69] D. A. Brown and M. P. Caulfield, "Hyperpolarizing "alpha 2"adrenoceptors in rat sympathetic ganglia," British Journal of Pharmacology, vol. 65, no. 3, pp. 435-445, 1979.

[70] C. Schmauss, D. L. Hammond, J. W. Ochi, and T. L. Yaksh, "Pharmacological antagonism of the antinociceptive effects of serotonin in the rat spinal cord," European Journal of Pharmacology, vol. 90, no. 4, pp. 349-357, 1983. 
[71] T. L. Yaksh and P. R. Wilson, "Spinal serotonin terminal system mediates antinociception," Journal of Pharmacology and Experimental Therapeutics, vol. 208, no. 3, pp. 446-453, 1979.

[72] L. He, M. Wang, M. Gao, and J. Zhou, "Expression of C-fos protein in serotonergic neurons of rat brainstem following electroacupuncture," Acupuncture and Electro-Therapeutics Research, vol. 17, no. 4, pp. 243-248, 1992.

[73] Q. P. Ma, Y. Zhou, Y. X. Yu, and J. S. Han, "Electroacupuncture accelerated the expression of $\mathrm{c}$-fos protooncogene in serotonergic neurons of nucleus raphe dorsalis," International Journal of Neuroscience, vol. 67, no. 1-4, pp. 111-117, 1992.

[74] R. S. S. Cheng and B. Pomeranz, "Electroacupuncture analgesia could be mediated by at least two pain-relieving mechanisms; Endorphin and non-endorphin systems," Life Sciences, vol. 25, no. 23, pp. 1957-1962, 1979.

[75] L. D. Aimone, S. L. Jones, and G. F. Gebhart, "Stimulationproduced descending inhibition from the periaqueductal gray and nucleus raphe magnus in the rat: mediation by spinal monoamines but not opioids," Pain, vol. 31, no. 1, pp. 123-136, 1987.

[76] T. S. Jensen and T. L. Yaksh, "Spinal monoamine and opiate systems partly mediate the antinociceptive effects produced by glutamate at brainstem sites," Brain Research, vol. 321, no. 2, pp. 287-297, 1984.

[77] M. M. Morgan, M. S. Gold, J. C. Liebeskind, and C. Stein, "Periaqueductal gray stimulation produces a spinally mediated, opioid antinociception for the inflamed hindpaw of the rat," Brain Research, vol. 545, no. 1-2, pp. 17-23, 1991.

[78] G. Zorman, G. Belcher, J. E. Adams, and H. L. Fields, "Lumbar intrathecal naloxone blocks analgesia produced by microstimulation of the ventromedial medulla in the rat," Brain Research, vol. 236, no. 1, pp. 77-84, 1982.

[79] M. Tsuchiya, H. Yamazaki, and Y. Hori, "Enkephalinergic neurons express $5-\mathrm{HT}_{3}$ receptors in the spinal cord dorsal horn: single cell RT-PCR analysis," NeuroReport, vol. 10, no. 13, pp. 2749-2753, 1999.

[80] H. K. Proudfit, "Effects of raphe magnus and raphe pallidus lesions on morphine-induced analgesia and spinal cord monoamines," Pharmacology Biochemistry and Behavior, vol. 13, no. 5, pp. 705-714, 1980.

[81] J. S. Han and L. Terenius, "Neurochemical basis of acupuncture analgesia," Annual Review of Pharmacology and Toxicology, vol. 22, pp. 193-220, 1982.

[82] L. Bardin, M. Bardin, J. Lavarenne, and A. Eschalier, "Effect of intrathecal serotonin on nociception in rats: influence of the pain test used," Experimental Brain Research, vol. 113, no. 1, pp. 81-87, 1997.

[83] E. J. A. Scherder and A. Bouma, "Possible role of the Nucleus Raphe Dorsalis in analgesia by peripheral stimulation: theoretical considerations," Acupuncture and Electro-Therapeutics Research, vol. 18, no. 3-4, pp. 195-205, 1993.

[84] T. Shimizu, "Effects of peripheral electric stimulation on the central 5-hydroxytryptamine in mice: relation to the peripheral stimulation-produced analgesia," Folia Pharmacologica Japonica, vol. 77, no. 4, pp. 347-360, 1981.

[85] Z.-Q. Zhao, "Neural mechanism underlying acupuncture analgesia," Progress in Neurobiology, vol. 85, no. 4, pp. 355-375, 2008.

[86] A. A. Alhaider, S. Z. Lei, and G. L. Wilcox, "Spinal 5-HT receptor-mediated antinociception: possible release of GABA," Journal of Neuroscience, vol. 11, no. 7, pp. 1881-1888, 1991.
[87] T. Crisp, J. L. Stafinsky, L. J. Spanos, M. Uram, V. C. Perni, and H. B. Donepudi, "Analgesic effects of serotonin and receptorselective serotonin agonists in the rat spinal cord," General Pharmacology, vol. 22, no. 2, pp. 247-251, 1991.

[88] R. Radhakrishnan, E. W. King, J. K. Dickman, C. A. Herold, N. F. Johnston, M. L. Spurgin et al., "Spinal 5- $\mathrm{HT}_{2}$ and $5-\mathrm{HT}_{3}$ receptors mediate low, but not high, frequency TENS-induced antihyperalgesia in rats," Pain, vol. 105, no. 1-2, pp. 205-213, 2003.

[89] H. Horiuchi, T. Ogata, T. Morino, J. Takeba, and H. Yamamoto, "Serotonergic signaling inhibits hyperalgesia induced by spinal cord damage," Brain Research, vol. 963, no. 1-2, pp. 312-320, 2003.

[90] J. Takagi and N. Yonehara, "Serotonin receptor subtypes involved in modulation of electrical acupuncture," Japanese Journal of Pharmacology, vol. 78, no. 4, pp. 511-514, 1998.

[91] P. K. Eide and K. Hole, "Different role of $5-\mathrm{HT}_{1 \mathrm{~A}}$ and 5$\mathrm{HT}_{2}$ receptors in spinal cord in the control of nociceptive responsiveness," Neuropharmacology, vol. 30, no. 7, pp. 727-731, 1991.

[92] T. Oyama, M. Ueda, Y. Kuraishi, A. Akaike, and M. Satoh, "Dual effect of serotonin on formalin-induced nociception in the rat spinal cord," Neuroscience Research, vol. 25, no. 2, pp. 129-135, 1996.

[93] W. Xu, X. C. Qiu, and J. S. Han, "Serotonin receptor subtypes in spinal antinociception in the rat," Journal of Pharmacology and Experimental Therapeutics, vol. 269, no. 3, pp. 1182-1189, 1994.

[94] S. R. Glaum, H. K. Proudfit, and E. G. Anderson, "5-HT receptors modulate spinal nociceptive reflexes," Brain Research, vol. 510, no. 1, pp. 12-16, 1990.

[95] D. Paul, D. Yao, P. Zhu, L. D. Minor, and M. M. Garcia, "5Hydroxytryptamine3 $\left(5-\mathrm{HT}_{3}\right)$ receptors mediate spinal 5-HT antinociception: an antisense approach," Journal of Pharmacology and Experimental Therapeutics, vol. 298, no. 2, pp. 674-678, 2001.

[96] Y. B. Peng, Q. Lin, and W. D. Willis, “The role of 5-HT 3 receptors in periaqueductal gray-induced inhibition of nociceptive dorsal horn neurons in rats," Journal of Pharmacology and Experimental Therapeutics, vol. 276, no. 1, pp. 116-124, 1996.

[97] Q. Lin, Y. B. Peng, and W. D. Willis, "Antinociception and inhibition from the periaqueductal gray are mediated in part by spinal 5-hydroxytryptamine(1A) receptors," The Journal of Pharmacology and Experimental Therapeutics, vol. 276, no. 3, pp. 958-967, 1996.

[98] L. Bardin, J. Schmidt, A. Alloui, and A. Eschalier, "Effect of intrathecal administration of serotonin in chronic pain models in rats," European Journal of Pharmacology, vol. 409, no. 1, pp. 37-43, 2000.

[99] S. M. Garraway and S. Hochman, "Pharmacological characterization of serotonin receptor subtypes modulating primary afferent input to deep dorsal horn neurons in the neonatal rat," British Journal of Pharmacology, vol. 132, no. 8, pp. 1789-1798, 2001.

[100] S. M. Garraway and S. Hochman, "Serotonin increases the incidence of primary afferent-evoked long-term depression in rat deep dorsal horn neurons," Journal of Neurophysiology, vol. 85, no. 5, pp. 1864-1872, 2001.

[101] M. J. Millan, S. Girardon, and K. Bervoets, "8-OH-DPATinduced spontaneous tail-flicks in the rat are facilitated by the selective serotonin (5-HT) ${ }_{2 C}$ agonist, RO 60-0175: blockade of its actions by the novel $5-\mathrm{HT}_{2 C}$ receptor antagonist SE 206,553," Neuropharmacology, vol. 36, no. 4-5, pp. 743-745, 1997. 
[102] R. E. Coggeshall and S. M. Carlton, "Receptor localization in the mammalian dorsal horn and primary afferent neurons," Brain Research Reviews, vol. 24, no. 1, pp. 28-66, 1997.

[103] C.-Y. Chiang and M. Zhuo, "Evidence for the involvement of a descending cholinergic pathway in systemic morphine analgesia," Brain Research, vol. 478, no. 2, pp. 293-300, 1989.

[104] B. E. Jones, M. Pare, and A. Beaudet, "Retrograde labeling of neurons in the brain stem following injections of $[3 \mathrm{H}]$ choline into the rat spinal cord," Neuroscience, vol. 18, no. 4, pp. 901-916, 1986.

[105] J.-H. Hwang, K.-S. Hwang, J.-K. Leem, P.-H. Park, S.-M. Han, and D.-M. Lee, "The antiallodynic effects of intrathecal cholinesterase inhibitors in a rat model of neuropathic pain," Anesthesiology, vol. 90, no. 2, pp. 492-499, 1999.

[106] E. T. Iwamoto and L. Marion, "Characterization of the antinociception produced by intrathecally administered muscarinic agonists in rats," Journal of Pharmacology and Experimental Therapeutics, vol. 266, no. 1, pp. 329-338, 1993.

[107] M. Naguib and T. L. Yaksh, "Antinociceptive effects of spinal cholinesterase inhibition and isobolographic analysis of the interaction with $\mu$ and $\alpha_{2}$ receptor systems," Anesthesiology, vol. 80, no. 6, pp. 1338-1348, 1994.

[108] Y. Wang, S. Wang, and J. Wu, "Effects of atropine on the changes of pain threshold and contents of leucine-enkephalin and catecholamines of the brain in rats induced by EA," Journal of Traditional Chinese Medicine, vol. 12, no. 2, pp. 137-141, 1992.

[109] M. Zhuo and G. F. Gebhart, "Tonic cholinergic inhibition of spinal mechanical transmission,” Pain, vol. 46, no. 2, pp. 211222, 1991.

[110] G. R. Lauretti and I. C. P. R. Lima, "The effects of intrathecal neostigmine on somatic and visceral pain: improvement by association with a peripheral anticholinergic," Anesthesia and Analgesia, vol. 82, no. 3, pp. 617-620, 1996.

[111] G. R. Lauretti, M. P. Reis, W. A. Prado, and J. G. Klamt, "Doseresponse study of intrathecal morphine versus intrathecal neostigmine, their combination, or placebo for postoperative analgesia in patients undergoing anterior and posterior vaginoplasty," Anesthesia and Analgesia, vol. 82, no. 6, pp. 1182-1187, 1996.

[112] C. Ghelardini, N. Galeotti, and A. Bartolini, "Loss of muscarinic antinociception by antisense inhibition of M1 receptors," British Journal of Pharmacology, vol. 129, no. 8, pp. 1633-1640, 2000.

[113] K. Honda, K. Koga, T. Moriyama, M. Koguchi, Y. Takano, and H.-O. Kamiya, "Intrathecal $\alpha_{2}$ adrenoceptor agonist clonidine inhibits mechanical transmission in mouse spinal cord via activation of muscarinic M1 receptors," Neuroscience Letters, vol. 322, no. 3, pp. 161-164, 2002.

[114] K. Koga, K. Honda, S. Ando, I. Harasawa, H.-O. Kamiya, and Y. Takano, "Intrathecal clonidine inhibits mechanical allodynia via activation of the spinal muscarinic M1 receptor in streptozotocin-induced diabetic mice," European Journal of Pharmacology, vol. 505, no. 1-3, pp. 75-82, 2004.

[115] M. F. Belin, M. Aguera, and M. Tappaz, "GABA-accumulating neurons in the nucleus raphe dorsalis and periaqueductal gray in the rat: a biochemical and radioautographic study," Brain Research, vol. 170, no. 2, pp. 279-297, 1979.

[116] D. B. Reichling and A. I. Basbaum, "Contribution of brainstem GABAergic circuitry to descending antinociceptive controls: II. Electron microscopic immunocytochemical evidence of GABAergic control over the projection from the periaqueductal gray to the nucleus raphe magnus in the rat," Journal of Comparative Neurology, vol. 302, no. 2, pp. 378-393, 1990.
[117] D. B. Reichling and A. I. Basbaum, "Contribution of brainstem GABAergic circuitry to descending antinociceptive controls: I. GABA-immunoreactive projection neurons in the periaqueductal gray and nucleus raphe magnus," Journal of Comparative Neurology, vol. 302, no. 2, pp. 370-377, 1990.

[118] J. Sandkuhler, E. Willmann, and Q.-G. Fu, "Blockade of GABA(A) receptors in the midbrain periaqueductal grey abolishes nociceptive spinal dorsal horn neuronal activity," European Journal of Pharmacology, vol. 160, no. 1, pp. 163-166, 1989.

[119] Q. Lin, Y. B. Peng, and W. D. Willis, "Role of GABA receptor subtypes in inhibition of primate spinothalamic tract neurons: difference between spinal and periaqueductal gray inhibition," Journal of Neurophysiology, vol. 75, no. 1, pp. 109-123, 1996.

[120] M. Malcangio and N. G. Bowery, "GABA and its receptors in the spinal cord," Trends in Pharmacological Sciences, vol. 17, no. 12, pp. 457-462, 1996.

[121] J. R. T. Silva, M. L. Silva, and W. A. Prado, "Analgesia induced by 2- or 100-Hz electroacupuncture in the rat tail-flick test depends on the activation of different descending pain inhibitory mechanisms," Journal of Pain, vol. 12, no. 1, pp. 51-60, 2011.

[122] G. W. Price, G. P. Wilkin, M. J. Turnbull, and N. G. Bowery, "Are baclofen-sensitive GABA(B) receptors present on primary afferent terminals of the spinal cord?” Nature, vol.307, no. 5946, pp. 71-74, 1984.

[123] M. J. Millan, "The induction of pain: an integrative review," Progress in Neurobiology, vol. 57, no. 1, pp. 1-164, 1999.

[124] J. Sawynok, "GABAergic mechanisms of analgesia: an update," Pharmacology Biochemistry and Behavior, vol. 26, no. 2, pp. 463-474, 1987.

[125] J. S. Han, J. Tang, and M. F. Ren, "Central neurotransmitters and acupuncture analgesia," American Journal of Chinese Medicine, vol. 8, no. 4, pp. 331-348, 1980.

[126] K. Fusumada, T. Yokoyama, T. Miki et al., "C-Fos expression in the periaqueductal gray is induced by electroacupuncture in the rat, with possible reference to GABAergic neurons," Okajimas Folia Anatomica Japonica, vol. 84, no. 1, pp. 1-10, 2007.

[127] L.-W. Fu and J. C. Longhurst, "Electroacupuncture modulates vlPAG release of GABA through presynaptic cannabinoid CB1 receptors," Journal of Applied Physiology, vol. 106, no. 6, pp. 1800-1809, 2009.

[128] S. C. Tjen-A-Looi, P. Li, and J. C. Longhurst, "Processing cardiovascular information in the vlPAG during electroacupuncture in rats: roles of endocannabinoids and GABA," Journal of Applied Physiology, vol. 106, no. 6, pp. 1793-1799, 2009.

[129] L. Zhu, C. Li, B. Yang, C. Ji, and W. Li, “The effect of neonatal capsaicin on acupuncture analgesia-to evaluate the role of $\mathrm{C}$ fibers in acupuncture analgesia," Acupuncture Research, vol. 15, no. 4, pp. 285-291, 1990.

[130] L. X. Zhu, C. Y. Li, C. F. Ji, and Q. Yu, "Involvement of GABA in acupuncture analgesia," Acupuncture research, vol. 11, no. 2, pp. 126-131, 1986.

[131] M. J. Millan, “The role of descending noradrenergic and serotoninergic pathways in the modulation of nociception: focus on receptor multiplicity," in The Pharmacology of Pain, Handbook of Experimental Pharmacology, A. Dickenson and J. M. Besson, Eds., vol. 130, pp. 385-446, Springer, Berlin, Germany, 1997.

[132] Z. Bing, F. Cesselin, S. Bourgoin, A. M. Clot, M. Hamon, and D. Le Bars, "Acupuncture-like stimulation induces a heterosegmental release of Met-enkephalin-like material in the rat spinal cord," Pain, vol. 47, no. 1, pp. 71-77, 1991.

[133] J. A. DeLeo and R. P. Yezierski, "The role of neuroinflammation and neuroimmune activation in persistent pain," Pain, vol. 90, no. 1-2, pp. 1-6, 2001. 
[134] V. Raghavendra, F. Tanga, and J. A. Deleo, "Inhibition of microglial activation attenuates the development but not existing hypersensitivity in a rat model of neuropathy," Journal of Pharmacology and Experimental Therapeutics, vol. 306, no. 2, pp. 624-630, 2003.

[135] J. Wang, H. Zhao, Q.-L. Mao-Ying, X.-D. Cao, Y.-Q. Wang, and G.-C. Wu, "Electroacupuncture downregulates TLR2/4 and pro-inflammatory cytokine expression after surgical trauma stress without adrenal glands involvement," Brain Research Bulletin, vol. 80, no. 1-2, pp. 89-94, 2009.

[136] Y. Shir and Z. Seltzer, "A-fibers mediate mechanical hyperesthesia and allodynia and C-fibers mediate thermal hyperalgesia in a new model of causalgiform pain disorders in rats," Neuroscience Letters, vol. 115, no. 1, pp. 62-67, 1990.

[137] P. Penza, M. Bricchi, A. Scola, A. Campanella, and G. Lauria, "Electroacupuncture is not effective in chronic painful neuropathies," Pain Medicine, vol. 12, no. 12, pp. 1819-1823, 2011.

[138] Y. Tong, H. Guo, and B. Han, "Fifteen-day acupuncture treatment relieves diabetic peripheral neuropathy," JAMS Journal of Acupuncture and Meridian Studies, vol. 3, no. 2, pp. 95-103, 2010. 


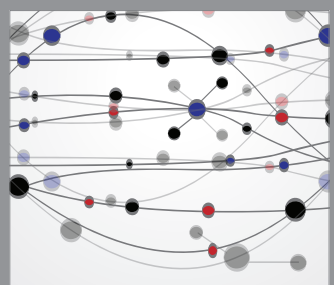

The Scientific World Journal
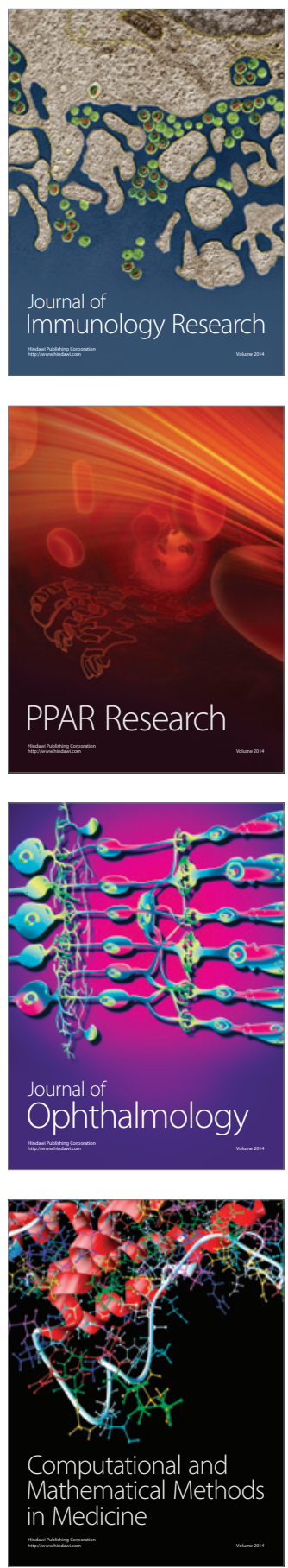

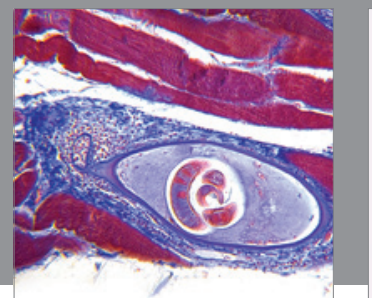

Gastroenterology

Research and Practice
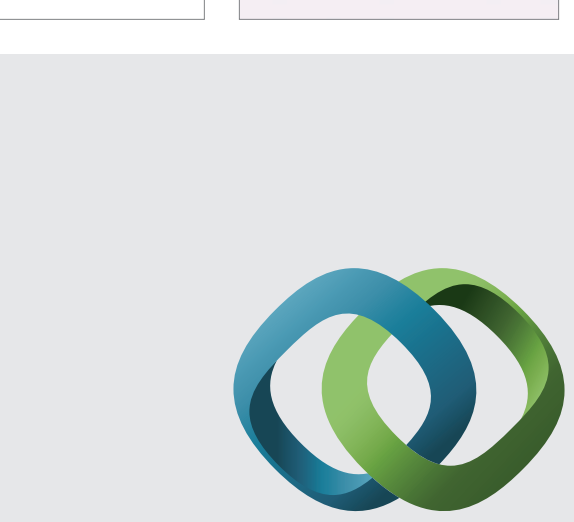

\section{Hindawi}

Submit your manuscripts at

http://www.hindawi.com
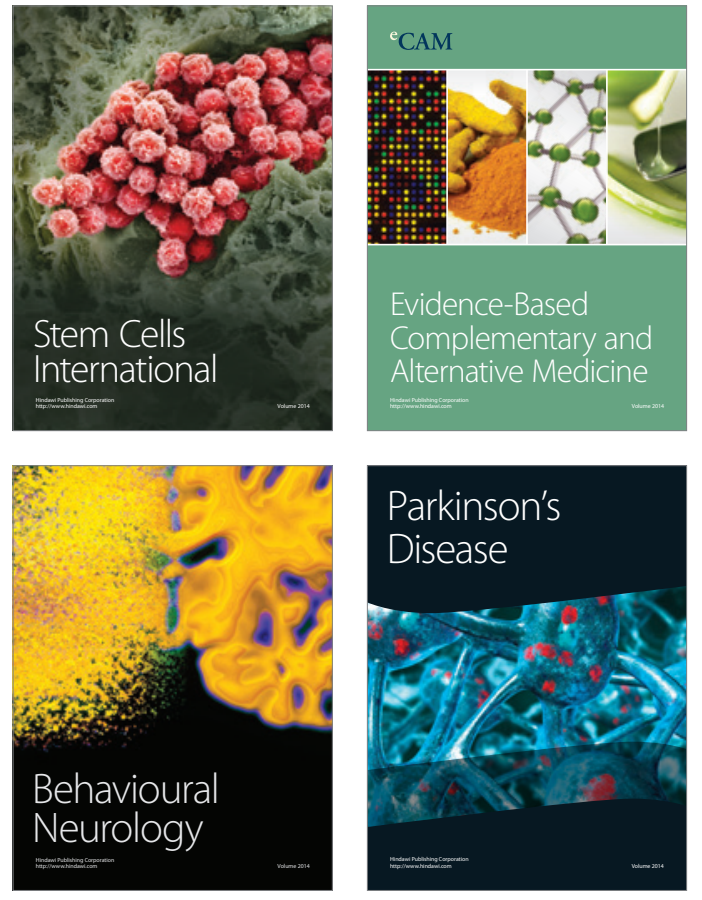
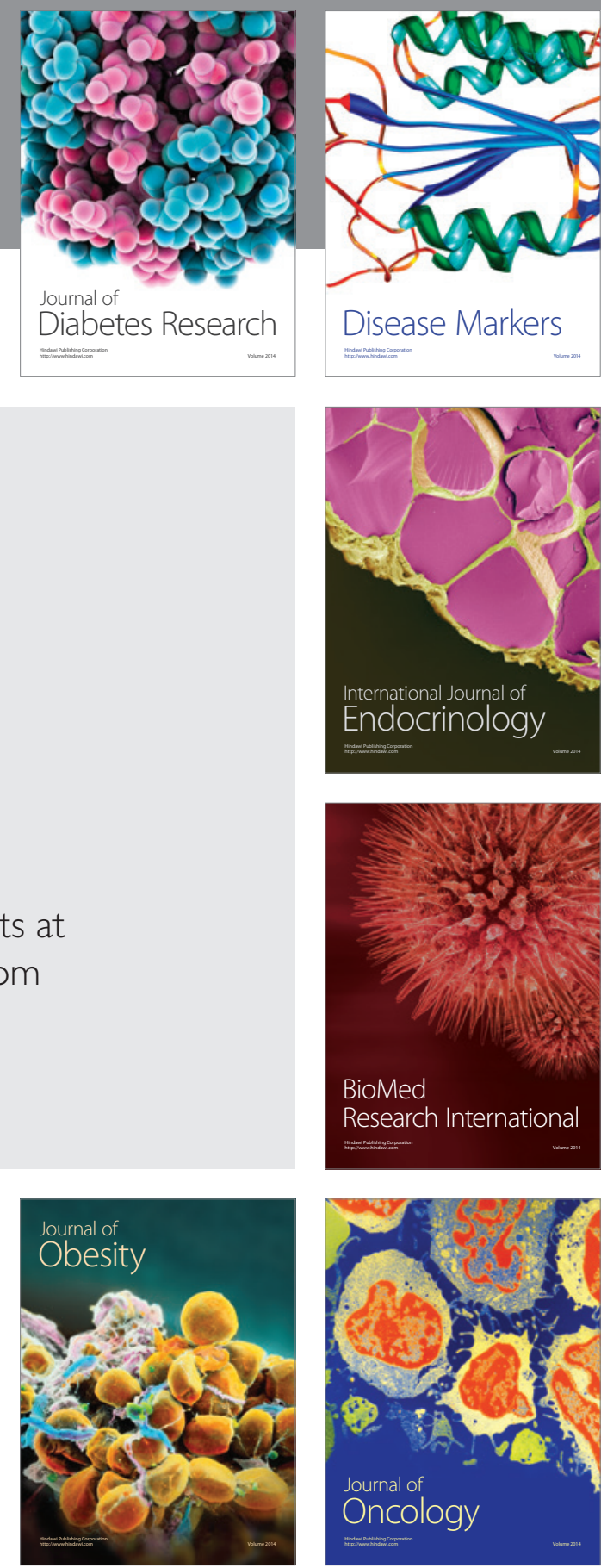

Disease Markers
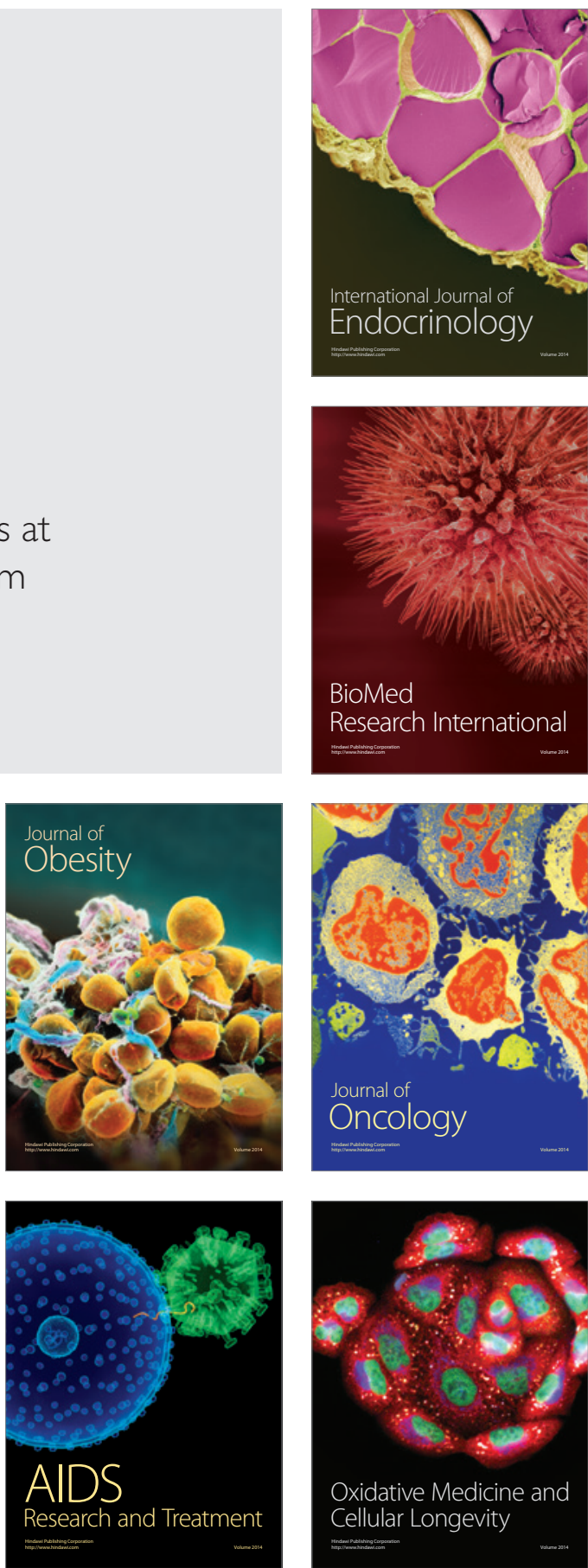